\title{
Anodic Behavior of III-V Semiconductors in Liquid Ammonia (223 K)
}

\author{
O. Seitz, C. Mathieu, A.-M Gonçalves" , M. Herlem, A. Etcheberry \\ IREM (Institut Lavoisier), Université de Versailles St Quentin, Bât. Lavoisier, \\ 45 Av. des Etats Unis, 78035 Versailles Cedex. France
}

Received 16 July 2002; Accepted in revised form 25 October 2002

\begin{abstract}
In liquid ammonia, the anodic behavior of $n$ - and p-type III-V semiconductors are strongly different from those observed in aqueous media. For both types, the anodic process in liquid ammonia involves the formation of an adsorbed film, onto the semiconductor surface just before its dissolution. This film results from the chemisorption of $\mathrm{N}$ atoms, issued from the oxidation of the solvent.
\end{abstract}

Keywords: semiconductors III-V, liquid ammonia oxidation.

\section{Introduction}

Many questions concerning the interface semiconductor/water have been solved or became clearer from ammonia liquid studies. For instance, this non aqueous solvent was appropriate to the comprehension of cathodic decomposition on III-V semiconductors [1] and also to study oxygen reduction mechanism [2]. Ammonia has been characterized as the water-like solvent, among both organic and inorganic compounds. In liquid ammonia, the protons are solvated by ammonia molecules, because of $\mathrm{NH}_{3}$ basicity: ammonium ion is the strongest acid and amide ion is the strongest base. At room temperature liquid ammonia is a very strongly basic solvent [3] $\left(10^{11}\right.$ times stronger than water) and it is a very weak acid ( $10^{29}$ times weaker than water) [3].

In recent years, many works have been performed in non-aqueous solvents in order to study the corrosion of semiconductors. Abshere et al. [4,5] had clearly demonstrated the fact that the photocorrosion of GaAs is ruled by traces of water in anhydrous methanol.

\footnotetext{
* Corresponding author. E-mail address: goncalve@chimie.uvsq.fr
} 
The use of non-aqueous solvents such as $\mathrm{MeCN}, \mathrm{DMF}$, DMSO which are never waterfree at the inferface, has lost all interest for this study, since the anodic behavior of the semiconductor can be ruled by traces of water. Liquid ammonia again provides us the opportunity to study the anodic electrochemical behavior of a semiconductor without water molecules at the interface since it can be purchased with an electronic grade quality.

\section{Experimental}

Ammonia ("electronic grade": 99.9999 \%) was obtained from Air Liquide. The cell and the equipment for condensing ammonia have already been described [6]. The volume of liquid ammonia was approximately $150 \mathrm{~cm}^{3}$, and the cell was maintained at $223 \mathrm{~K}$ in a cryostat. The acidic medium was obtained by addition of $\mathrm{NH}_{4} \mathrm{Br}$ (purest available quality from Aldrich). $\mathrm{NH}_{4} \mathrm{Br}$ provides at the same time the acidification of the medium and the electrical conductivity of the solution. Unbuffered neutral medium was obtained by $0.1 \mathrm{M}$ of $\mathrm{KBr}$.

III-V semiconductor wafers with a $<100>$ orientation were purchased from MCP Electronic Materials, Ltd. A doping density of $10^{17}-10^{18} \mathrm{~cm}^{-3}$ was used. The wafers were cut into small squares $\left(0.5 \times 0.5 \mathrm{~cm}^{2}\right)$. Prior to use, the semiconductors were chemomechanically polished with a solution of bromine in methanol (1\%), rinsed with methanol and dried under an argon stream. The p-type electrodes were illuminated with white light from a $150 \mathrm{~W}$ tungsten lamp by means of an optical fibber. The light intensity was regulated by optical grey filters [7]. A smooth Pt electrode (Tacussel) used as a stationary electrode was a $1 \mathrm{~mm}$ diameter disk. Before use it was polished with alumina paste, cleaned, rinsed with water and dried under an argon stream.

The medium deoxygenation was performed under an argon stream. All potentials were measured against a silver reference electrode (SRE) [6]. The oxygenation of the medium was performed under an oxygen stream. The electrochemical set-up was a classical three-electrode device with linear scan of potential of $20 \mathrm{mV} / \mathrm{s}$.

Quantitative analysis was performed after liquid ammonia evaporation at room temperature and addition of $150 \mathrm{~mL}$ of acidic solution of $\mathrm{H}_{2} \mathrm{SO}_{4}(1 \mathrm{M})$. Gallium and arsenic analysis was performed by atomic spectroscopy with an accuracy of $0.1 \mu \mathrm{g} / \mathrm{L}$. 


\section{Results and Discussion}

At a smooth platinum electrode, the anodic current results from the oxidation of ammonia molecules according to the following reaction $[8,9]$ :

$$
\mathrm{NH}_{3} \rightarrow \mathrm{N}_{2}+3 \mathrm{H}^{+}+3 \mathrm{e}^{-}
$$

No limitation of the solvent oxidation was observed at a smooth Pt electrode (Fig. 1A). Unlike III-V semiconductors no oxidation wave was detected before this unlimited current. The question remains open and still unexplored as regard to the anodic behaviors of III-V semiconductors in liquid ammonia.

Whatever the III-V semiconductors (GaAs, InP, GaP) and for both types ( $\mathrm{n}$ - and p-), an anodic peak was observed in the dark (Fig. 1B). The anodic peak was located just before an unlimited current. In the unlimited current range, two electrochemical behaviors were clearly distinguished on the one hand by a gaseous evolution onto $\mathrm{Pt}$ electrode and on the other hand by the semiconductor dissolution. Whatever the type of semiconductor a dissolution occurs as soon as high current densities are reached, that is to say in the unlimited range of current. This dissolution was clearly visible to the naked eye. MEB picture indicates clearly a strong dissolution of the semiconductor after its polarization in the unlimited range current densities. Whatever the III-V semiconductors and for both types, the position of the anodic peak as well as the implied coulometric charge were perfectly reproducible. For both types a coulometric charge of $4 \times 10^{-3}$ $\mathrm{C} / \mathrm{cm}^{2}$ to $7 \times 10^{-3} \mathrm{C} / \mathrm{cm}^{2}$ was associated to the anodic peak.

During the reverse scan, for both types, the anodic peak does not reappear again. A large range of potential without current results from this anodic treatment. An overpotential of $1 \mathrm{~V}$ is almost observed for both types after scanning the anodic peak. The increase of potential range without current suggests a modification of the semiconductor/liquid ammonia interface after the anodic treatment. The anodic treatment induced a total electric blocking at the semiconductor/liquid ammonia interface in this range of potential.

The anodic peak disappears completely after one scan, while the anodic wall does not shift. Onto GaAs-n a reduction peak connected to the anodic peak appears clearly before the proton reduction (Fig. 2). The current density of the anodic peak as well as its associated cathodic peak were directly proportional to scan rate. These current peaks 
were not limited by diffusion phenomena but rather by adsorption phenomena. Only one scan on this reduction peak is sufficient to recover the anodic peak in acidic medium. In unbuffered medium, where protons are not present, the initial state cannot be recovered.

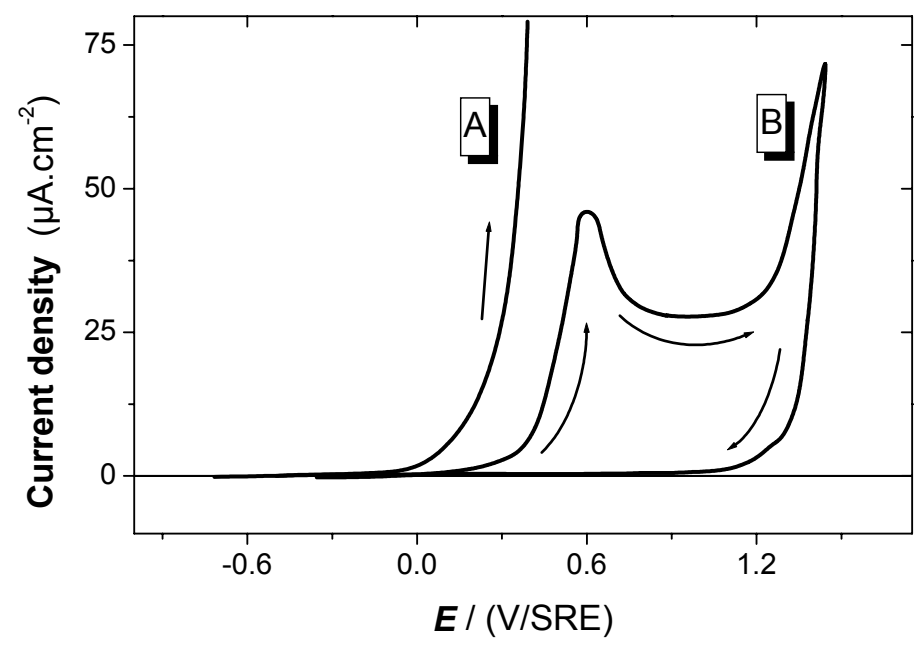

Figure 1. Liquid ammonia $(223 \mathrm{~K}) \cdot\left[\mathrm{NH}_{4} \mathrm{Br}\right]=3.2 \times 10^{-2} \mathrm{M}$. V $=20 \mathrm{mV} / \mathrm{s}$. A- Platinum electrode. B-GaAs-p.

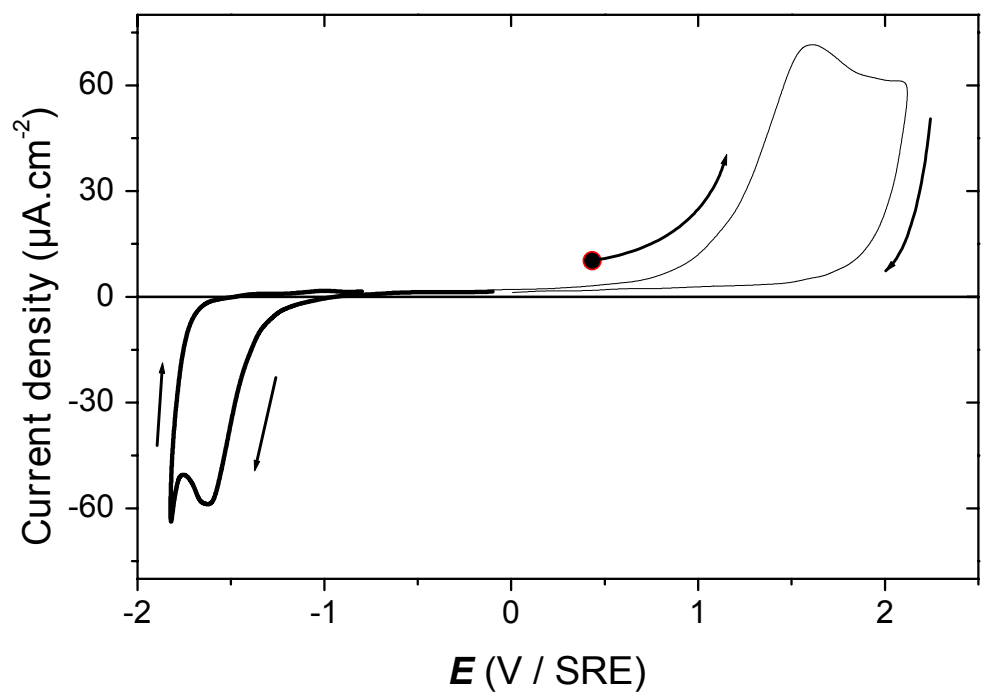

Figure 2. Liquid ammonia $(223 \mathrm{~K}) .\left[\mathrm{NH}_{4} \mathrm{Br}\right]=3.2 \times 10^{-2} \mathrm{M} . \mathrm{V}=20 \mathrm{mV} / \mathrm{s}$. GaAs-n semiconductor.

We tried to understand what was occurring under this anodic peak. It leads one to suppose whether an oxidation of the solvent, whether a semiconductor dissolution like in aqueous media (with the coating of the electrode by an insoluble compound issued 
from the acid reaction of one or both material elements onto $\mathrm{NH}_{3}$ ), or an oxidation of the solvent with a dissolution of the semiconductor.

For high current densities (higher than $6 \mathrm{~mA} / \mathrm{cm}^{2}$ ), quantitative analysis has been performed. Like in aqueous media, semiconductor dissolution might occur through the following mechanism [10]:

$$
\mathrm{GaAs}+6 \mathrm{~h}^{+} \rightarrow \mathrm{Ga}^{3+}+\mathrm{As}^{3+}
$$

Knowing the coulometric charge implied in the anodic treatment and the quantity of $\left(\mathrm{Ga}^{3+}, \mathrm{As}^{3+}\right)$ species found from quantitative analysis, the ratio of holes required for the dissolution can be determined during the anodic process. These analyses have been done in the unlimited current. A linear relation was established between the anodic coulometric charge and the element weigh (gallium and arsenic) determined from quantitative analysis. For high current densities $\left(>6 \mathrm{~mA} / \mathrm{cm}^{2}\right)$, we can assume that 90 to $100 \%$ of the anodic coulometric charge are included in the anodic semiconductor dissolution.

The great difficulty was to analyze products from the anodic peak since semiconductor surface became deactivated until reaching a null current value. This difficulty is partially bypassed by fixing a low anodic current density. Intentiostatic measurements were performed on the beginning of the ascent of the unlimited current. For high current density $\left(6 \mathrm{~mA} / \mathrm{cm}^{2}\right)$, still $80 \%$ of the anodic charge is implied in the semiconductor dissolution (Table 1). However, for low current density $\left(0.1 \mathrm{~mA} / \mathrm{cm}^{2}\right)$, only $55 \%$ of the anodic charge is used for the semiconductor dissolution. According to these differences, we can assume that less than $55 \%$ of the coulometric charge of the anodic peak is implied in the semiconductor dissolution.

Table 1. Ratio of semiconductor dissolution against anodic current density.

\begin{tabular}{ccccc}
\hline $\begin{array}{c}\text { Current density } \\
\mathbf{J}\end{array}$ & $\mathrm{J}>6 \mathrm{~mA} / \mathrm{cm}^{2}$ & $\mathrm{~J}=2 \mathrm{~mA} / \mathrm{cm}^{2}$ & $\mathrm{~J}=0.5 \mathrm{~mA} / \mathrm{cm}^{2}$ & $\mathrm{~J}=0.1 \mathrm{~mA} / \mathrm{cm}^{2}$ \\
\hline $\begin{array}{c}\text { Ratio of SC } \\
\text { dissolution }\end{array}$ & $90-100 \%$ & $\sim 78 \%$ & $\sim 75 \%$ & $\sim 55 \%$ \\
\hline
\end{tabular}

The oxidation of aqueous ammonia has been studied at metallic electrodes [11,12]. Although the presence of water, and like for GaAs semiconductor, an anodic peak was also observed for noble metals (Pt, $\mathrm{Ru}, \mathrm{Pd}, \mathrm{Ir}$ and $\mathrm{Ru}$ ) as well as for Al. It was clearly 
showed that a deactivation of the electrode surface was observed during ammonia oxidation by $\mathrm{N}$ atoms adsorbed strongly onto the metal surface. By analogy with these results we assumed that on III-V semiconductors the oxidation of the solvent can occur before the dissolution of the material. We supposed that two different and sequential reactions occur through the anodic peak and the unlimited current.

Firstly: oxidation of $\mathrm{NH}_{3}$ molecules, leading to an adsorbed film of $\mathrm{N}$ atoms on the electrode surface, like for some metallic electrodes in aqueous ammonia [11,12].

Secondly: oxidation of the electrode material. The higher the anodic current, the lower the ammonia oxidation.

We discarded the formation of an insulating coating of the electrode by a compound resulting from an acid-base reaction of one oxidized element coming from the material electrode, for example:

$$
\mathrm{Ga}^{3+}+6 \mathrm{NH}_{3} \rightarrow \mathrm{Ga}\left(\mathrm{NH}_{2}\right)_{3}[\text { insoluble }]+3 \mathrm{NH}_{4}^{+}
$$

Consequently we assumed that an adsorbed film resulting from ammonia oxidation blocked the surface semiconductor just before its dissolution.

\section{Conclusion}

We showed that the anodic peak could result from the adsorption of nitrogen intermediate, which behaves as a surface poison during the electrochemical oxidation of ammonia, but the formation of insoluble amides on the electrode surface could also play a role. This work pointed out the fact, for the first time that the oxidation of the solvent can occur on a small gap semiconductor before the dissolution of the semiconductor.

\section{References}

1. A. Etcheberry, A-M. Gonçalves, C. Mathieu, M. Herlem, J. Electrochem. Soc. 144 (1997) 928.

2. A.M. Gonçalves, C. Mathieu, M. Herlem, A. Etcheberry. J. Electroanal. Chem. 462 (1998) 88 .

3. see for example: J. Jander, Anorganische und allgemeine Chemie in flüssigen Ammoniak. Part I, Friedr. Vieweg \& Sohn, Braunschweig, 1966.

4. T. A. Abshere, G. L. Richmond, J. Phys. Chem., B 103 (1999) 7911. 
5. T. A. Abshere, G. L. Richmond, J. Phys. Chem. B 104 (2000) 1602.

6. D. Guyomard, C. Mathieu, M. Herlem, J. Electroanal. Chem. 246 (1988) 29.

7. A-M. Gonçalves, C. Mathieu, M. Herlem, A. Etcheberry. J. Electroanal. Chem. 420 (1997) 25.

8. J. J. Minet, M. Herlem, A. Thiébault, G. Favé, J. Electroanal. Chem. 33 (1971) 69.

9. J. J. Minet, M. Herlem, A. Thiébault, J. Electroanal. Chem. 31 (1971) 153.

10. P.H.L. Notten, J.E.A.M. Van Den Meerakker, J. J. Kelly, Etching of III-V semiconductors, Elsevier, Oxford, 1991.

11. H. Gerischer, A. Mauerer, J. Electroanal. Chem. 25 (1970) 421.

12. A.C.A. de Vooys, M.T.M. Kper, R.A. van Santen, J.A.R. van Veen, J. Electroanal. Chem. 506 (2001) 127. 